Supplement of Adv. Geosci., 44, 9-13, 2017

http://www.adv-geosci.net/44/9/2017/

doi:10.5194/adgeo-44-9-2017-supplement

(C) Author(s) 2017. CC Attribution 3.0 License.

(c) (i)

Advances in
Geosciences

Supplement of

\title{
Human-flood interactions in Rome over the past 150 years
}

\section{Giuliano Di Baldassarre et al.}

Correspondence to: Giuliano Di Baldassarre (giuliano.dibaldassarre@geo.uu.se)

The copyright of individual parts of the supplement might differ from the CC-BY 3.0 licence. 


\section{Supplementary material: 1) Data and 2) Model code}

\section{Data}

\begin{tabular}{cc}
\hline Year & Flood peak levels (m) \\
\hline 1805 & 16.42 \\
1846 & 16.25 \\
1870 & 17.22 \\
1900 & 16.17 \\
1915 & 16.08 \\
1937 & 16.84 \\
\hline \multicolumn{2}{|}{} \\
\hline Year & Floodplain Population \\
\hline 1871 & 109210 \\
1901 & 173629 \\
1931 & 334116 \\
1951 & 473802 \\
1981 & 609857 \\
1991 & 582819 \\
2001 & 583286 \\
2014 & 567959 \\
\hline
\end{tabular}

\section{Model code in $\mathbf{R}$}

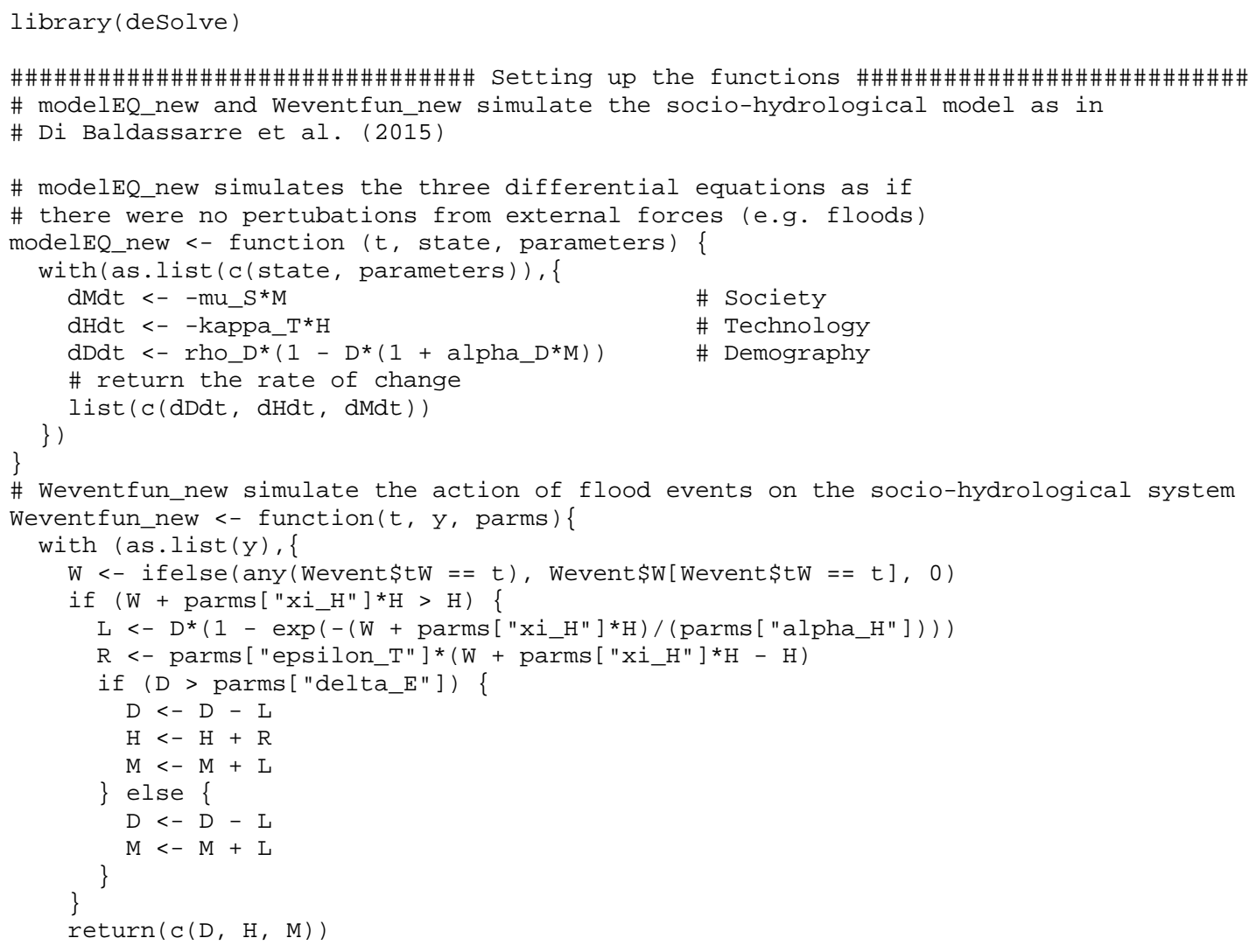




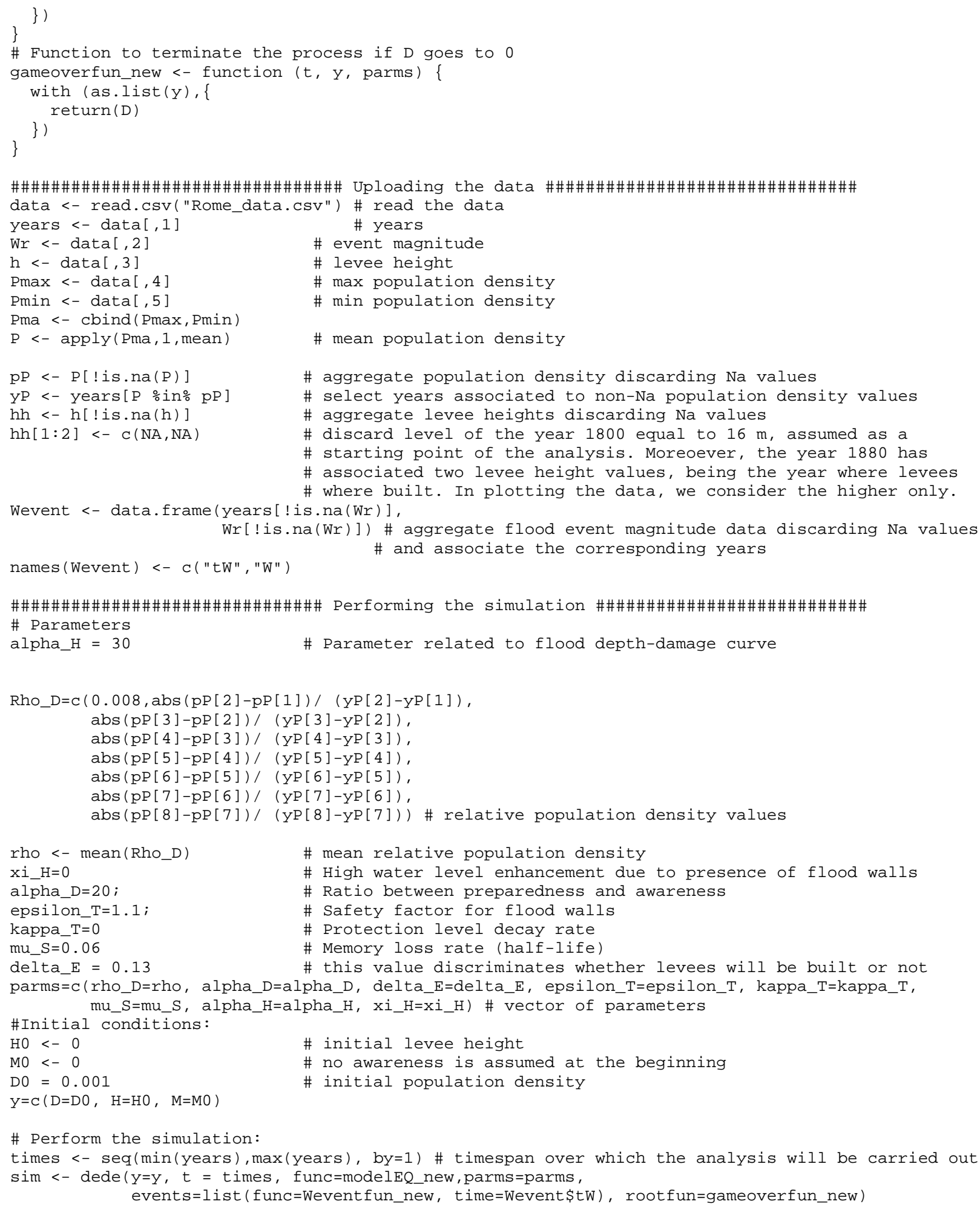

